\title{
LOS JÓVENES POPULARES URBANOS FRENTE A LA PRENSA ESCRITA Y DIGITAL: DISTORSIONES, IDENTIFICACIONES, DISTANCIAS Y SILENCIOS
}

\author{
VÍCTOR MUÑOZ TAMAYO * \\ CARLOS DURÁN M." \\ EDUARDO THAYER C.
}

\begin{abstract}
RESUMEN
Este artículo tiene como propósito exponer algunos de los principales resultados obtenidos de la realización de dieciséis grupos de discusión con jóvenes populares urbanos de cuatro regiones de Chile, referidos a sus percepciones, evaluaciones y niveles de identificación con la producción informativa de los medios de prensa escrita y digital. El artículo expone de qué forma los jóvenes manifiestan una fuerte desidentificación respecto a los contenidos y tratamiento informativo que la prensa escrita y digital desarrolla acerca de lo que definimos como «mundo juvenil popular».
\end{abstract}

PALABRAS CLAVE: JUVENTUD POPULAR, PLURALISMO, PRENSA

* Doctor en Estudios Latinoamericanos, investigador proyecto Anillo, Universidad de Chile. E-Mail: vmtamayo@u.uchile.cl.

** Doctor en Ciencias Sociales, académico Facultad de Historia y Ciencias Sociales, Universidad Diego Portales, Santiago, Chile.

E-Mail: carlos.duranm@mail.udp.cl.

*** Doctor en Sociología, investigador asociado Centro de Investigación en Sociedad y Políticas Públicas, Universidad de Los Lagos, Santiago, Chile. E-Mail: eduardo.thayer@gmail.com.

Este artículo fue realizado en el marco de la ejecución del estudio «Jóvenes populares y pluralismo en medios escritos. Estudio de percepción, lectoría y evaluación del pluralismo en la prensa escrita y digital», que formó parte del Fondo de Estudios sobre el Pluralismo en el Sistema Informativo Nacional 2013, financiado por el Consejo Nacional de Ciencia y Tecnología (CONICYT), Gobierno de Chile. 


\title{
OS JOVENS POPULARES URBANOS SOBRE A MÍDIA IMPRESSA \\ E DIGITAL: DISTORÇÕES, IDENTIFICAÇÕES, DISTÂNCIAS E SILÊNCIOS
}

\begin{abstract}
RESUMO
Este artigo tem como objetivo apresentar alguns dos principais resultados obtidos da realização de 16 grupos de discussão com jovens populares urbanos de quatro regiões do Chile, sobre suas percepções, avaliações e níveis de identificação com a produção informativa da mídia impressa e digital. O artigo expõe de que maneira os jovens manifestam uma forte desidentificação a respeito dos conteúdos e do tratamento informativo que a mídia impressa e digital desenvolve sobre o que definimos como "mundo jovem popular".

PALAVRAS CHAVE: JUVENTUDE POPULAR, VLURALISMO, IMPRENSA

\section{URBAN POPULAR YOUNG PEOPLE FACING DIGITAL AND PRINT MEDIA: DISTORTIONS, IDENTIFICATIONS, DISTANCES AND SILENCES}

\begin{abstract}
This article aims to present some of the main results obtained from the performance of 16 discussion groups with urban popular young people from four regions of Chile, related to their perceptions, evaluations and levels of identification with the informative production of digital and print media. This article describes how young people present a strong disidentification to the contents and news coverage developed by print and online media about what we define as «popular young world».
\end{abstract}

KEY WORDS: POPULAR YOUTH, PLURALISM, PRESS 


\section{INTRODUCCIÓN}

El Mercurio y los diarios grandes yo los uso para envolver el pescado... no me interesan para nada.

(Hombre, grupo 9)

EN EL PRESENTE ARTÍCULO nos proponemos exponer algunos de los avances y conclusiones generados de la realización, en el marco del estudio «Jóvenes populares y pluralismo en medios escritos. Estudio de percepción, lectoría y evaluación del pluralismo en la prensa escrita y digital», de un conjunto de grupos de discusión realizados con diversidades juveniles adscritas al mundo popular en torno al tópico de la prensa escrita y digital y su relación con las temáticas e identidades juveniles.

Este estudio se propuso una aproximación a los niveles de expresión del atributo del pluralismo informativo respecto a los jóvenes populares urbanos chilenos, tanto desde la perspectiva de la producción informativa de los medios de prensa escrita y digital como de las percepciones, recepciones y apropiaciones que los propios jóvenes realizan respecto a dicha producción.

En este artículo, se exponen las conclusiones referidas específicamente a las percepciones subjetivas producidas por jóvenes populares participantes de dieciséis grupos de discusión realizados en la Región Metropolitana, de Los Lagos, del Maule y del Bío-Bío, en los cuales se abordó la temática de la relación entre estos jóvenes y la prensa escrita y digital, lo que incluía:

a) Sus percepciones respecto a los atributos que definen a la prensa escrita y digital;

b) Su evaluación de los distintos medios de prensa informativa; y

c) Sus valoraciones acerca de la forma en que esta aborda el tópico juvenil, en general, y la realidad de los jóvenes populares urbanos, en lo específico.

Este texto se encuentra organizado en cuatro partes: en la primera, damos cuenta de algunos de los criterios con los cuales realizamos el encuadre teórico-metodológico de este estudio; en la segunda, exponemos las principales conclusiones en lo que refiere a las percepciones y evaluaciones respecto a los medios de prensa escrita y digital; en la tercera parte, nos concentramos en las evaluaciones y valoraciones relativas a 
los niveles de identificación entre la producción informativa de los medios de prensa escrita y digital y la especificidad de los mundos juveniles desde los cuales se agencian los sujetos partícipes de los grupos de discusión; en la cuarta y última parte, ofrecemos un conjunto de conclusiones aproximativas relativas al vínculo que — desde la perspectiva de los actores-, es posible establecer entre prensa escrita y digital y jóvenes populares urbanos.

\section{CONSIDERACIONES TEÓRICO-METODOLÓGICAS}

El estudio del pluralismo en los medios de prensa constituye una agenda temática ampliamente desarrollada en el ámbito de las ciencias sociales y de la comunicación (de Bustos, 2004; Murciano, 2007; Ruiz-Tagle, 2011; Sierra, 1997). Este concepto, al igual que otros como los de democracia, libertad o solidaridad, forma parte de un conjunto especial de significantes de tipo evaluativo-descriptivo (Skinner, 1973). Es decir, un tipo de conceptos que en su sola enunciación contienen una disposición valórica asociada.

Esta naturaleza del concepto pluralismo, por consecuencia, vuelve altamente compleja la tarea de evaluar, medir o comprender la forma en que - en un determinado contexto social - este atributo se expresa. Las estrategias para abordar este difícil concepto, a nuestro juicio, son posibles de distinguir en función de dos definiciones fundamentales, las que se distinguen de acuerdo a su concentración en la producción informativa, los unos, o bien en la recepción social de dichas producciones, los otros.

En el primer caso, el pluralismo constituye una función de la diversidad de perspectivas, intereses, concepciones y expresiones valóricas posibles de detectar en un determinado sistema informativo. Un sistema informativo plural, en este sentido, es uno en el que coexiste una variedad significativa de medios representativos a su vez de la diversidad sociopolítica y cultural propios de una determinada sociedad. Esta estrategia de abordaje del pluralismo, por consecuencia, centra la mirada en lo que podemos comprender como la pluralidad de fuentes productoras de información, a diferencia de la segunda perspectiva, según la cual la comprensión del pluralismo se relacionaría más bien con el campo de la recepción que el conjunto social - diverso y heterogéneo- genera respecto a dichas producciones informativas.

Es justamente desde esta segunda perspectiva que este trabajo adquiere sentido, toda vez que asume la pluralidad del sistema infor- 
mativo nacional, y en lo específico de la prensa escrita y digital, como un indicador posible de ser observado desde el conjunto de percepciones sociales que sobre dicho sistema circulan. Un sistema informativo plural, en este sentido, no es solo un conjunto de medios diversos que «expresen» consecuentemente la variedad de realidades y significaciones acerca de lo social, sino que además un sistema que logre ser recepcionado como tal, que «refleje» la diversidad desde la propia perspectiva de los sujetos sociales.

Dirigido en esta búsqueda por dar cuenta del campo de la recepción y consecuente evaluación del pluralismo en la prensa escrita y digital chilena, este estudio se concentró en un sector específico de la diversidad socioestructural chilena, a saber: el de los jóvenes populares urbanos.

Para los efectos de este estudio, entenderemos la categoría «juventud» como una condición vinculada a factores sociales, biológicos, vitales, históricos y simbólicos. Por lo mismo, si bien existen ciertos consensos en torno a tramos etarios que corresponderían a «la juventud» - entre catorce y diecisiete años, hasta veintinueve años, por ejemplo-, ya sea como sector vinculado a cierto estatus jurídico o a unidad de análisis estadístico, es claro que tanto la duración como el carácter y las edades (cronología) de esta condición etaria, se deben en gran parte a una definición producida por la sociedad, por lo que lejos de implicar la existencia de un grupo definido y homogéneo, da cuenta de una pluralidad de «juventudes» en correspondencia con los sentidos y significados otorgados a la etapa juvenil, a la condición que la antecede (niñez) y a la posterior (adultez).

Por lo mismo, entendemos la juventud como una condición plural y cruzada por múltiples distinciones que operan en las sociedades: una diversidad conectada tanto con los modos de representar a las juventudes (la construcción social, ideológica y simbólica de estas) como con posiciones e identidades (mundos juveniles) mediadas por las diferenciaciones socioeconómicas, étnicas y de género (Bourdieu, 1990; Margulis y Urresti, 1996). En este sentido, entendemos la juventud como categoría etaria que sugiere una heterogeneidad marcada por una intensa búsqueda identitaria asociada a la construcción de proyectos existenciales. Tal realidad es heterogénea, y la tensión existencial que implica es distinta dependiendo de cómo se dé y asuma la relación entre las ofertas de inserciones laborales futuras, las metas y sueños construidos a nivel de cada sujeto, y una situación socioeconómica que condiciona las posibilidades de tales proyectos. 
La especificidad «jóvenes populares», por su parte, cubre aquellos mundos en donde las tensiones características de la juventud se viven bajo las marcas de la incertidumbre y la carencia (Duarte 2001), de modo que se asocia a variadas posiciones (estudiantes, trabajadores), adscripciones (organizaciones, agrupamientos) e identificaciones (estilos, culturas) en donde dichas marcas definen la juventud vivida. En tal sentido, nuestra concepción de lo popular se asocia a la exclusión y carencia económica (primeros quintiles socio económicos), pero en su relación con la vivencia cultural de tales inequidades sociales; es decir, en referencia a la producción de «mundos» en donde se viven y proyectan determinados modos de ser joven en sociedad.

Para cumplir con los objetivos propuestos en este estudio es que nos propusimos la realización de un conjunto de grupos de discusión que tuvieran como tópico justamente el de las percepciones y evaluaciones relativas al sistema informativo nacional, y en lo específico a la prensa escrita y digital, con la participación de sujetos asociados a la caracterización arriba descrita respecto a lo juvenil popular. ¿Cómo definen los jóvenes populares chilenos a la producción informativa chilena? ¿Existen diferencias significativas en las evaluaciones que realizan respecto a los medios informativos? ¿Qué tan representados o distantes se posicionan respecto a la producción informativa referida a los sectores juveniles en generales, y a los jóvenes populares urbanos en lo específico? ¿Consideran los jóvenes que los medios de información representan la diversidad social?

La operativización de estos objetivos se realizó resguardando un doble criterio de homogeneidad y heterogeneidad. Primero, la totalidad de los grupos debían estar conformados por jóvenes adscritos a los que más arriba hemos definido como «mundo popular» y segundo, debían presentar algunos criterios que los diferenciaran internamente, atendiendo a la posibilidad de capturar diferentes posicionamientos que nos indicaran la existencia de determinados factores estructurantes de la subjetividad juvenil popular.

En relación a este segundo criterio, se optó por la realización de grupos de discusión que a) distinguieran entre grupos de distintos tramos etarios; b) consideraran el factor género; c) distinguieran entre jóvenes adscritos identitariamente a distintas condiciones (estudiantes, trabajadores, organizados y adscritos a algún estilo juvenil específico) y d) que incorporaran la distinción territorial (jóvenes de la Región Metropolitana, de Los Lagos, del Maule y del Bío-Bío). 
En total, entre los meses de mayo y agosto del año 2014, este estudio organizó dieciséis grupos de discusión, en los que participaron cerca de un centenar de jóvenes en una dinámica conversacional que, para el cumplimiento de los objetivos propuestos, combinó la activación de juicios, evaluaciones y percepciones espontáneas con la producción de estímulos activadores (cuasi-experimentales) referidos a unidades noticiosas consideradas por el equipo de investigación como ilustrativas de la forma en que la prensa escrita y digital aborda los tópicos juveniles, en general, y al mundo juvenil popular, en lo específico.

El resultado fue la producción de un conjunto denso y saturado de argumentos, posicionamientos y valoraciones relativas al tópico que acá nos ocupa, y respecto al cual haremos referencia en las páginas que siguen.

\section{LAS JUVENTUDES FRENTE A LA PRENSA ESCRITA Y DIGITAL: EVALUACIONES}

En este apartado, abordaremos las evaluaciones y significaciones de los jóvenes que participaron de los grupos de discusión en relación a la producción informativa de la prensa escrita y digital. En primera instancia, nos referiremos a las significaciones más recurrentes a la hora de describir y evaluar a la prensa, para luego exponer las evaluaciones y preferencias respecto a la oferta de medios informativos existentes en el país.

\section{a) Los jóvenes ante la prensa: generalizaciones y omisiones}

La distancia y desidentificación respecto a la producción informativa de la prensa en general $-\mathrm{y}$ de la prensa escrita en lo específico-, constituye una constante en la totalidad de los discursos juveniles que emergieron en los grupos de discusión realizados, con independencia de las diferencias etáreas, la variedad de mundos abordados, el género y las regiones de residencia. Con mayor o menor intensidad, los jóvenes que participaron de los grupos de discusión coinciden en relacionarse de modo distante con los sentidos, los contenidos y las formas informativas que circulan en la prensa escrita.

Las adjetivaciones respecto a las cuales existe consenso a la hora de caracterizar a la prensa escrita remiten, en lo fundamental, a cuatro ideas-fuerza: 
i) La naturaleza generalizadora y parcial de las informaciones respecto de una realidad que se muestra con desatención a los detalles, la diversidad y los contextos.

ii) La presencia recurrente de «mentiras» y distorsiones de la realidad en la agenda informativa de los medios escritos.

iii) El énfasis en los aspectos negativos de la realidad, y específicamente en los aspectos negativos de la realidad de los sectores populares.

iv) La tendencia a la exageración en el tratamiento de cierto tipo de noticias y la propensión a la espectacularidad por sobre la información.

Respecto a la primera idea-fuerza, los participantes de los grupos de discusión coinciden en la presencia en los medios de prensa de una tendencia a mostrar solo una parte de la «realidad», haciéndola ver como representativa del todo. La diversidad de realidades que se despliegan en la vida nacional, se señala de modo prácticamente unánime, no es representada en los medios de prensa, los que se concentran solo en una parte de ella, ya sea para generalizar «buenas noticias» como representativas de «toda la gente», o bien para destacar las «malas noticias» (delincuencia, violencia, drogadicción, vandalismo) como representativas de todo un sector social. Y es en este sentido que, se observa, los medios de prensa «reflejan una pequeña parte de lo que sucede dentro y fuera del país» (Oliver, grupo 7). Por ello es que, a la hora de evaluar la producción informativa de la prensa escrita, el juicio es que «todo lo que aparece en los periódicos se generaliza» $(\mathrm{Ca}-$ rolina, grupo 3).

Reiterados son en este sentido los comentarios que, como se observará en el apartado siguiente, ilustran el argumento de la generalización aludiendo a la identificación, por una parte, de situaciones de violencia, delincuencia o vandalismo como representativos de «los jóvenes en general» o de «los pobres en general»; y a la identificación de características de los «jóvenes de clase media» o de los «grupos privilegiados» y/o «los ricos» con «los jóvenes»o «los chilenos»en general. El juicio arriba expuesto decanta en la segunda idea fuerza arriba indicada: la prensa «miente y distorsiona»:

Son muy pocas las veces que he visto noticias que hablen de realidad, (de lo) que realmente está pasando, porque todo lo manosean. No se dice la verdad, mienten(Mara, grupo 2). 
Siempre esconden la verdad, nunca quieren hablar de la verdad [...] nunca se enfocan en la realidad de lo que pueden ver las personas (Yerko, grupo 14).

Lo otro es que también en estos medios [...] no muestran que tal persona de Las Condes atropelló una persona, o que tal hombre iba curao y le pusieron un parte y era de plata. Entonces, también se cargan pal lado de las clases más bajas (Rafael, grupo 15).

Muestran el delito en sí no más, no muestran si este niño tiene familia, nadie lo ha cuidado [...]. Tenía que salir a robar porque quizás no tenía para comer (Evelyn, grupo 5).

El sentimiento compartido de los jóvenes que formaron parte de los grupos, en este sentido, es que la información que expone la prensa no es verídica, no expone «la realidad tal cual». Tal como se verá en el apartado siguiente, este juicio relativo a la distorsión y falta de veracidad de la prensa escrita - y de los medios de comunicación en general- constituye la expresión de una percepción fuertemente arraigada según la cual la prensa escrita no constituye el medio más adecuado como para informarse respecto a lo que ocurre tanto a nivel nacional como local.

Ahora bien, esta percepción general relativa a la naturaleza «generalizadora» $\mathrm{y}$ «distorsionadora» de la prensa se materializa en las siguientes dos ideas-fuerza que, a juicio de los jóvenes, constituyen la ilustración y el motivo de la distancia con la prensa: el énfasis en los aspectos negativos de la realidad, por un lado, y la tendencia a la exageración y la espectacularidad, por el otro.

Respecto al primer elemento, se sostiene de modo recurrente que la agenda noticiosa de los medios escritos se focaliza en los aspectos negativos de la realidad:

De repente se da más auge a lo más malo que a lo bueno [...]. Se le da más auge de repente (al) vandalismo (Patricio G., grupo 6).

Con el mismo tema de las manifestaciones, todo ese tema de las marchas: cuando hay destrozos en las calles, solamente muestran eso, ese tema, no muestran lo bueno (Hombre 2, grupo 9).

Siempre aparecen las partes negativas (Alejandra, grupo 8). 
Las noticias están principalmente mostrando una desgracia, y para los jóvenes lo mismo: son destrozos en los liceos, que las marchas estudiantiles [...] no muestran lo bueno que pueden hacer los jóvenes cuando ayudan a la comunidad (Lorena, grupo 5).

En este punto, las evaluaciones relativas a la distorsión y generalización como dispositivos propios de la prensa escrita alcanzan su especificidad: no es que la prensa escrita derechamente informe respecto a eventos o situaciones que no ocurrieron, o que derechamente ficcione respecto a los hechos sobre los cuales informa, sino que más bien decide destacar la dimensión negativa de la realidad, los aspectos que muestran sobre todo a sectores específicos — «los jóvenes», «los pobres»— como depositarios de vicios y constitutivos de amenaza pública. Lo arriba expuesto se relaciona directamente con la cuarta y última idea-fuerza: la de la tendencia a la exageración y la espectacularidad:

Yo creo que los diarios le colocan mucho, le colocan más de su cosecha [...] puede ocurrir algo y ellos le ponen el triple más de lo que pasó. $\mathrm{O}$ sea, no son sinceros $[\ldots]$ ellos colocan mucho más $[\ldots]$ más malo (Josefa, grupo 7).

Muchas veces, hay gente que le pone de más po' y gente que le pone más cosas, o cosas que no están en la realidad, y le ponen más (Patricio T., grupo 6).

Yo creo que hay un poco de hiperbolización. O sea, debe haber algún grado de exageración para causar un poco más de placer al lector, a la gente que lee el periódico. Es una cuestión obvia: marcar un poco más, darle mayor connotación social para hacer ruido y, por lo tanto, vender más (Hombre 2, grupo 12). ${ }^{2}$

Esta tendencia a la conversión de la noticia en espectacularización de lo negativo, en una magnificación y un sentido morboso, es asociada fuertemente con la subordinación de los medios de prensa escrita a la necesidad de responder a las expectativas «de la gente», de satisfacer el interés público por acceder a noticias «espectaculares», que a juicio de los jóvenes son las noticias que «venden»:

2 Cuando no se ha señalado el nombre de pila de algún entrevistado, hemos optado por mencionar el sexo y un número que lo identifique entre los asistentes de quienes conforman cada grupo. 
Muestran culpables y se apunta bastante con el dedo en la noticia. Por un lado para vender más, porque a la gente le gusta el morbo: le gusta saber lo que pasa, dónde sucede, quien lo hace y de cierta forma se generaliza un poco la noticia. La noticia ahora se entiende como algo que tiene que llamar la atención más que sea algo importante. Mientras más llamen la atención, mientras más resalten, y usualmente por razones obscenas, más gente la va a leer y más se va a comprar el diario, y eso obedece a términos económicos (Oliver, grupo 7).

Ellos se enfocan en lo que más vende [...] como lo que más llama la atención (Carlos, grupo 5).

A la final es como que se enfocan en lo que posiblemente podría interesarle a la gente, porque yo he visto que la gente se interesa más en las cosas negativas, en lo que están de acuerdo ellos, con su percepción de los jóvenes, que (en) las cosas positivas. Porque si la prensa informara, por ejemplo, de que hay jóvenes que se esfuerzan [...] jóvenes que se esfuerzan y que luchan por salir adelante $[. .$.$] si pusieran eso en las no-$ ticias, como que a la gente no le interesa mucho. Entonces, igual eso es un tema, yo creo, como de captar público, así como enfocarse en los temas que a la gente le interesa más(Jocelyn, grupo 6).

De acuerdo a estas percepciones, la prensa operaría como simple reproductor de las demandas noticiosas de los ciudadanos, las cuales se caracterizarían por la búsqueda por consumir morbo, espectacularidad y banalidad, demandas que serían satisfactoriamente cumplidas por la prensa, en desmedro de su función informativa.

En definitiva, y en lo que refiere a esta caracterización general de la disposición de los jóvenes respecto a la prensa escrita y su producción informativa, resulta digna de destacar la transversalidad observada en las evaluaciones arriba reseñadas. Se trate de hombres o mujeres, habitantes de la Región Metropolitana o de Los Lagos, Maule o Bío-Bío, se trate de estudiantes, trabajadores, miembros de organizaciones o adscritos a algún estilo juvenil, y con independencia a la edad, es posible observar una fuerte homogeneidad en la identificación de la prensa escrita con los atributos antes nombrados de la generalización, la mentira, la concentración en los aspectos negativos y la exageración.

Ahora bien, esta disposición general y compartida, expresada además en la coincidencia respecto a la baja presencia de hábitos de lectoría de prensa escrita, manifiesta algunas diferencias y tonalidades dignas de ser abordadas, las que dan cuenta de variaciones respecto a 
las motivaciones y significaciones que acompañan la distancia entre jóvenes y prensa. En este sentido, fue posible observar la presencia, al interior de los grupos y de manera transversal a los mismos, de un conjunto de argumentaciones que, compartiendo las evaluaciones ya descritas, las articulaban con una fundamentación crítica respecto a la configuración del orden social en general. Es decir, argumentaciones que trascendían a la diagnosis acerca de la prensa escrita, evidenciando la conexión entre esta y condiciones de desigualdad, opresión y desigualdad características de la sociedad chilena en general.

Este último conjunto de argumentaciones - posibles de identificar a su vez como un subconjunto al interior del universo configurado por las percepciones respecto a la prensa escrita - busca profundizar en las razones y sentidos que explican la disposición de la prensa escrita frente a la realidad social chilena. En esta dirección es que se visibilizan nuevas ideas-fuerza, esta vez asociadas con la voluntad de comprender de modo crítico las motivaciones del no cumplimiento de la labor informativa de la prensa escrita. Estas ideas-fuerza pueden sintetizarse en los conceptos de «colusión con el poder económico y político» y «encubrimiento de la realidad».

Respecto a la primera idea, emerge en este subconjunto crítico el argumento de que las distorsiones, omisiones y generalizaciones de la prensa escrita responden a una situación de expresa colusión entre sus intereses y los del poder político y económico más que a simples incapacidades o ineficiencias:

Las noticias [...] creo que están totalmente coludidas con el Estado, la prensa en general (Josefa, grupo 7).

Uno se hace la idea de que la prensa, por lo menos a nivel de diarios por ejemplo, las que son de mayor tránsito nacional, [...] son diarios que no informan (sino) que desinforman. Y eso también es una política, ahí también hay una intencionalidad. O sea, si me vai a preguntar qué noticias son realmente importantes para Chile en Las Últimas Noticias, te aseguro que el $90 \%$ del diario no informa [...] y creo que (frente a) esa desinformación hay muchos de los jóvenes que leen y dicen: no, este diario no me está diciendo nada de lo que realmente pasa (Hombre 4, grupo 12).

Como los medios están controlados, los que realmente les tienen miedo a la generación de ahora son las personas que están a la cabeza, y con- 
taminan el medio que la demás gente lee para poder generar una especie de virus (Paulina, grupo 16).

Yo creo que lo otro que ha jugado fuerte en contra, por llamarlo de alguna forma, es el hecho que los mismos grupos políticos y económicos son los que manejan los periódicos escritos. Por ejemplo, el grupo este Copesa, (que) maneja todo, (y que) en realidad son los dueños de la mayoría de lo que nosotros leemos o encontramos en el quiosco. Entonces, al final, su forma de presentar la noticia son las mismas, cambian solamente los titulares (Sonia, grupo 8).

Lo que se muestra es lo que le conviene a la clase dominante (Jandy, grupo 16).

Yo creo que también hay un poco de miedo desde los centros de poder - por decirlo así- de esta juventud que tiene ideas en sí muy «utópicas» $[\ldots]$ y quizás eso a los medios de comunicación les asusta. Obviamente, los medios de comunicación que se encuentran controlados les asusta en sí que los jóvenes tengan este control, o estén empezando a tomar este control y a sentirse parte de generar los cambios (Carolina, grupo 16).

La ausencia de información veraz y la desidentificación con la producción de la prensa escrita, en este sentido, constituyen una respuesta a las condiciones, intereses e inequidades que operan en el plano social más que al resultado de decisiones, insuficiencias o incapacidades de la propia prensa.

Coincidente con esta asociación entre prensa y poder políticoeconómico, esta argumentación avanza en la línea de identificar los déficits informativos de la prensa escrita como el efecto de una voluntad explícita de «distorsionar» la realidad, de «ocultar» y/o de «desinformar» respecto a «lo que realmente pasa en el país»:

[...] encubre lo grande pero resalta lo pequeño, pero lo pequeño es la nube fantasiosa que se supone que está todo bien (...) Yo creo que está mal hecha la pega, porque no muestran todo, muestran solamente una pequeña fracción, para tratar de manejar lo que es la opinión pública. Nosotros sabemos que [...] el periodista puede ser un muy buen profesional, integral, todo, pero tiene un jefe también, y desde ahí es donde parte todo porque pasa por la editorial y tiene que ser aprobado también (Mujer 4, grupo 10). 
Los medios más globales, los más utilizados, como son la televisión, yo creo que lo que hacen un poco es enmascarar temas países, distraen a la población en realidad. Las mismas noticias sobre farándula, harto deporte. Entonces, yo creo que en cuanto a tema país (se trata de) enmascarar. Desinforman a la población (Cristian, grupo 7).

Creo que los medios en realidad dan como dos puntos de vista: por un lado, dan una imagen o un modelo, como que sería el modelo perfecto a seguir. A los niños, a las personas más chicas le hacen ver un tipo de persona que tu debierais ser, como modelo perfecto [...] de una línea, que vea más ropa de marca, que no piense, que su mente no la lleve mucho más allá de lo que puede ser. Y por otro tipo, creo que claramente se te que ocultan varias cosas en realidad, (cosas que) no muestran ( $\mathrm{Ni}$ colás, grupo 7).

¿Qué es lo que no se dice? O sea, la intención verdadera, el trasfondo de los verdaderos problemas que están pasando [...] Y ¿por qué?. O sea, si está rompiendo material público o si se están quemando micros es una respuesta social a todas las necesidades que no están satisfechas (Carlos, grupo 1).

Entonces, eso (la delincuencia) muchas veces lo utilizan los medios de comunicación como para generar este enemigo interno, para generar esta consternación, [...] incubarla dentro de la sociedad. Y al final de cuentas se propaga incluso (en) las cuestiones más mínimas, como por ejemplo condenar a un cabro chico (Hombre 4, grupo 11).

Que los medios manifiestan una naturaleza «tendenciosa» es una afirmación que aparece de modo frecuente en esta disposición argumentativa. Lo tendencioso, en este sentido, pasa a ser entendido como aquello que presenta una intencionalidad oculta, una intencionalidad que a su vez se representa en la «distorsión» de las noticias por parte de los medios de prensa en función de intereses que favorecen a los grupos dominantes de la sociedad, entendiendo por ello la comunión indiferenciada entre grupos económicos y élites políticas.

En definitiva, esta línea argumentativa de naturaleza crítica permite evidenciar la presencia de un criterio específico de distinción al interior de los grupos de discusión que formaron parte de este estudio, criterio que, como dijimos, no se encuentra correlacionado con criterio estructural alguno. En otras palabras: a la hora de evaluar en términos generales a la prensa escrita, los jóvenes populares coinciden en un conjunto de ideas-fuerza compartidas, y se distinguen en función de la 
presencia o no de una argumentación crítica con la cual dichas ideasfuerza se articulan.

\section{b) Preferencias, proximidades y lejanías: prensa escrita y digital}

Las consideraciones generales respecto a la producción de la prensa escrita y digital que manifiestan los jóvenes se suplementan con evaluaciones específicas a partir de las cuales es posible distinguir algunas tonalidades y variaciones a la hora de determinar las preferencias y los niveles de cercanía y lejanía respecto al conjunto de medios. En lo general, en cada grupo se manifestaban preferencias y evaluaciones específicas que, por su diversidad y variedad, no lograron constituir materia de acuerdo entre los propios grupos, ni lograron constituirse como evidencia para la generación de conclusiones válidas. No obstante ello, se plantearon un conjunto de continuidades y consensos en las evaluaciones respecto a las cuales resulta interesante destacar las más significativas.

En primer lugar, resulta destacable la presencia del diario El Mercurio como la representación prototípica de la naturaleza lejana de la prensa. Los motivos de esta imputación van desde la identificación entre este medio y el poder económico, su cobertura privilegiada a grupos sociales considerados como lejanos, hasta la impugnación a su estilo y lenguaje:

Tú te leís un párrafo en El Mercurio y te quedai dormido (risas) ¿Hai hecho ese ejercicio? Te leís un párrafo de El Mercurio y te quedai dormido porque usan un lenguaje tan sofisticado que no es para nosotros (Hombre 1, grupo 9).

Es la idea de que si el joven no lee el mercurio no está informado y no le interesa, pero quién va a leer El Mercurio de nosotros si sabemos ya la realidad de cómo son estos medios y qué nos entregan. Para estar leyendo de economía, de cómo los ricos se llenan más los bolsillos de plata, no (Mujer 4, grupo 10).

A mí me pasa con un diario en particular, El Mercurio: que si uno va a su página social, uno se da cuenta que lo social que ellos tienen, así como la vida social, jes demasiado elitista (Italo, grupo 2).

Es así como, si existe un consenso a la hora de evaluar en lo específico a la prensa escrita, justamente éste aparece en la compartida eva- 
luación del periódico El Mercurio y su disposición lejana tanto respecto a los jóvenes como al mundo popular. Un periódico «de las élites y para las élites», en definitiva.

Por otro lado, interesante resulta la fuerte presencia de alusiones al periódico La Cuarta, representada como un medio con mayor capacidad de aproximación a los sentidos comunes de la ciudadanía, puesto que «al usar ese vocabulario más coloquial llega más a un sector más amplio de la gente» (Oliver, grupo 7). Dicha cercanía, sin embargo, no se traduce precisamente en una representación veraz de los sentires, necesidades y realidades de la ciudadanía, el mundo popular y de los jóvenes en específico. Por el contrario, esta proximidad se logra por medio de una representación «distorsionada» y «simplificada» de dichas realidades:

Primero que todo, es el diario que escribe más vulgar [...] le está dando un mal ejemplo a la población porque ya es un diario importante, se destaca en eso, y ver que la mayoría de la gente se siente identificada porque ocupan palabras [...] entonces la gente a la que va enfocada la noticia ya pasó a ser [...] ese diario al final lo compran caballeros, gente de las poblaciones $[\ldots]$ lo van a entender «al tiro» (Carlos, grupo 5).

[...] yo creo que puede ser más cercano por el tema del vocabulario (Evelyn, grupo 5).

A mi me da risa La Cuarta porque cree que la gente pobre [...] es ordinaria; o que la gente pobre quiere leer solamente sexo, fútbol y tiroteos. Entonces ahí hay como dos problemas: El Mercurio es demasiado elitista, solo un tipo de gente lo puede entender; y La Cuarta se ríe de los pobres (...) Más que informar a la clase popular, se ríe de los pobres [...] (Hombre 1, grupo 9).

Junto con esta distancia crítica respecto a los medios escritos en particular, y a la prensa en general, fue posible recabar coincidentes evaluaciones acerca de la valoración de los medios digitales como espacios más adecuados y veraces en lo que refiere a la representación del mundo juvenil/popular. Dichos medios, en lo fundamental, son concebidos como más cercanos, accesibles y representativos de la diversidad social del país: «Es que internet abarca todo: ahí leís el diario, noticias online» (Mujer 2, grupo 9).

Una primera ventaja de los medios digitales es su accesibilidad, cercanía y proximidad con las prácticas juveniles, cuestión esta última 
sumamente valorada por la mayoría de los jóvenes que formaron parte de los grupos de discusión:

[...] igual el adolescente, el joven, es un poco flojo entonces no va a ir al quiosco de la esquina a comprar un diario, preferible meterse a internet, y leerlo y estar ahí acostado con el notebook o con el celular, que es mucho más práctico (Hombre 2, grupo 8).

Yo creo que en la web también encuentro que se permite un poco más de información: suben más reportajes, suben más noticias. Uno se mete al portal de Terra, por ejemplo, y sigue bajando y siguen apareciendo nuevas noticias. Es una cuestión bastante desbordante como información, y ahí yo encontrado como de todo, experiencias más orientadas a los jóvenes (Valentina, grupo 2).

Interesante resulta la alusión permanente y sistemática a una asociación entre prensa digital y transparencia: «Yo creo que es más transparente ver algo en la web que un diario o en la tele» (Héctor, grupo 14). Con independencia del medio del que se trate, existe una asociación entre la prensa escrita y los medios informativos televisivos y la opacidad, y una consecuente asociación de la plataforma digital con un mayor nivel de transparencia y veracidad.

Ahora bien, esta mayor valoración de la prensa digital se encuentra directamente asociada al rol mediador que las redes sociales, especialmente Facebook, juegan al momento de producir el acceso de los jóvenes a los medios e información digitales. Es decir que, lo que aparece como una tenencia sumamente extendida, con independencia de cualquier factor estructural, es la conversión de las redes sociales en el medio más eficiente de acceso a la información por parte de los jóvenes:

En las redes de internet y todo, que nosotros somos los que más las usamos (más que los adultos), ahí se ven mucho más las noticias en relación a los intereses de uno. Por ejemplo, cosas que son llamativas para uno (Nicole, grupo 8).

Yo por lo menos me he sentido, por el tema del uso de las redes sociales, más cercano a las noticias. Antes no tenía acceso al diario, y lo único que leía cuando era más chico eran los que compraba mi papá no más, que compraba de repente en la casa. Yo nunca hice el ejercicio de ir a comprar un diario. Después de que salió internet me fui acercando más a la prensa (Hombre 1, grupo 12). 
Es el Facebook la plataforma porque te mezcla todo, ¿cahai? El Facebook es un buen negocio porque es un popurrí. Podís twittear y aparece en Facebook, y podís colgar links de lo que querai: interés personal, noticias. No falta el que pone «me gusta» al The Clinic, a las noticas del The Clinic, o el Soy Osorno (Hombre 2, grupo 11).

Junto a estos criterios de coincidencia, y al igual como ocurre en las evaluaciones respecto a la prensa en general, el posicionamiento de los jóvenes frente a los medios digitales también se ve expuesto a una especificidad constituida por valoraciones específicas de los así llamados «medios de información alternativos», nombrados por aquellos jóvenes vinculados a discursividades críticas. En este caso, la valoración del soporte digital opera realizando una distinción entre medios que simplemente reproducen las condiciones de la prensa escrita, y aquellos que «verdaderamente» se constituyen como una alternativa para el acceso a fuentes de información distintas a las convencionales:

Impresos no, los de internet yo creo que llegan más a la juventud. Igual, los medios tradicionales como los que están nombrados aquí no son los que tienen más llegada. Los alternativos en realidad son los que tienen más llegada (Mujer 1, grupo 10).

La mayoría de los medios masivos de comunicación, ya sea escrito, digital, televisivo o radio, todo el día hablan de farándula [...] yo como joven me da lo mismo, yo muchas veces prefiero no ver noticias o no informarme con esos medios de comunicación porque para mí muestran basura. Prefiero buscar cosas online que me muestren más cultura, más deportes, más cosas concretas que realmente a mí sí me interesan como joven (Carlos, grupo 5).

Yo con los medios que me informo, El Mostrador y El Ciudadano, nos alivia el internet de los 500 pesos que cuestan en los quioscos. $\mathrm{O}$ de los medios, de repente, que crean los mismos jóvenes, que crean sus medios para informar, pero no pueden competir contra El Mercurio y La Terce$r a$, contra ese duopolio [...] además que todos los diarios regionales son de El Mercurio y los otros son de COPESA. Entonces, no podís competir contra ese duopolio. Y ese duopolio de la información es el que te genera una imagen (Hombre 1, grupo 9).

O sea lo que más leo yo, las publicaciones que salen en Facebook, serían las de El Mostrador y El Ciudadano. Son los dos fuertes que están ahí informando constantemente, con información dura e importante, con trasfondo más social y cultural (Mujer 4, grupo 10). 
Yo sigo a varios grupos independientes de noticias que, de pronto, dependen de alguna universidad, algún centro de alumnos o alguna comunidad específica en algún sector determinado. Entonces, también eso da muestra de que ya no se cree en los medios canónicos y se están buscando formas alternativas de información (Hombre 4, grupo 12).

Yo creo, por ejemplo, que El Ciudadano, el The Clinic, El Mostrador, todos estos medios alternativos que son buenos, yo los considero súper. Mucho más profesionales que El Mercurio, por ejemplo, pero no tienen el alcance (Hombre 1, grupo 9).

En este conjunto de argumentaciones se observa una especificación mayor de la valoración universalmente compartida por los jóvenes respecto a los medios digitales. En este sentido, esta valoración de los medios alternativos de información concibe el espacio digital como un simple soporte que genera mayores posibilidades para la producción y circulación de informaciones que logren contrarrestar la concentración de la prensa escrita y la hegemonía de aquellas informaciones concebidas como distorsionadas, desinformadoras u ocultadoras.

\section{JUVENTUD Y JUVENTUD POPULAR. NOSOTROS EN LOS DIARIOS}

Como expresamos en la introducción a este texto, el presente estudio produjo una serie de conversaciones en que jóvenes populares, provenientes de múltiples realidades, identidades y contextos, desarrollaron una plática atendiendo a los siguientes problemas: ¿Cómo aparece la juventud en la prensa? ¿Qué nos identifica de sus contenidos noticiosos sobre los jóvenes? ¿Qué se dice sobre la juventud y qué se omite sobre su realidad? ¿Qué hay en los diarios sobre los jóvenes que habitan barrios como los nuestros, colegios como los nuestros? ¿Qué hay en cada página de diarios, periódicos y portales noticiosos de internet sobre la juventud que vivimos, sobre nuestra cotidianidad de jóvenes populares? ¿Cómo se presentan las prácticas, espacios y preocupaciones que compartimos? ¿Cómo aparecemos los que acudimos a los colegios municipales, los que trabajamos, o los que estudiamos y trabajamos para vivir y pagar una Universidad? ¿Cómo se describe a los que estamos en las esquinas poblacionales compartiendo nuestro estilo, nuestra música, nuestros gustos? ¿Estamos ahí en los diarios? ¿Estamos cuando se habla de juventud? ¿De qué modo estamos y en relación a qué contextos y temas se nos considera? 
Tales ejercicios de conversación nos llevaron a un terreno heterogéneo y complejo, pues lo que subyace a los contenidos abordados es la polisémica construcción que se hace de la categoría «juventud» en la prensa, en donde singularidades coexisten con totalizaciones relativas a los jóvenes chilenos, y en donde la descripción y tratamiento de las noticias se vincula a valorizaciones y rechazos; presencias y ausencias; ruidos y silencios que visibilizan e invisibilizan, destacan o etiquetan juventud. En relación a esa «construcción de juventud» que realiza la prensa, lo central ha sido su recepción, el modo en que dichas noticias han sido percibidas por una heterogeneidad de jóvenes populares. En ese sentido, se buscó dar luces sobre la situación de pluralismo de los medios frente a una juventud también plural, que expresa, en clave etaria, las distinciones, diferencias e inequidades presentes en la sociedad chilena. En definitiva, nos preocupó cómo la juventud acá estudiada interpreta los énfasis noticiosos y valoraciones asociadas a la polisémica y compleja categoría: «juventud chilena».

En este marco, un objetivo central ha sido conocer las percepciones en torno a cómo la prensa, a partir de alguna singularidad juvenil, totaliza refiriéndose a «la juventud chilena», y de cómo, por otro lado, se entiende que dicha prensa expone heterogeneidad juvenil, la nombra e interpreta como parte de realidades socioculturales diferentes. Asociado a lo anterior, interesa saber cómo los jóvenes populares entienden cómo sus propias realidades son presentadas en los medios escritos, aquellas vivencias de quienes sufren la desigual distribución de los bienes que la sociedad produce, la realidad juvenil de los sectores más pobres, de los que cargan con una mayor incertidumbre económica, viviendo con particular dramatismo las tensiones existenciales características de este grupo etario.

Tenemos entonces dos grandes problemas que fueron parte de las conversaciones sostenidas: primero, qué se muestra y se dice en la prensa escrita sobre la «juventud» cuando ella se trata en términos genéricos; segundo, de qué modo los jóvenes que reúnen las características asociadas a la juventud popular («nosotros»), están («estamos») presentes o ausentes en las construcciones noticiosas relativas a «la juventud chilena». Sobre ello, las conversaciones arrojaron percepciones que expondremos en forma de afirmaciones presentes en los discursos analizados. Estas percepciones refieren a determinadas dimensiones de lo que se observa en la prensa — algunas más genéricas y otras más específicas-, ya sea sobre la juventud, la juventud popular, o diversos «mundos juveniles populares» entendidos como identi- 
dades y posiciones heterogéneas presentes entre los jóvenes. Por cierto, varias de estas afirmaciones tienen en el discurso un tono categórico que por momentos es matizado o queda en tensión o contradicción con otras afirmaciones que complementan o profundizan en algunas de las dimensiones debatidas en relación al tratamiento de lo juvenil por parte de la prensa. En resumen, las siguientes afirmaciones constituyen las percepciones más recurrentes en los discursos juveniles analizados, y que en el formato de los grupos de discusión fueron articuladas como notorios consensos sobre los temas tratados.

\section{a) Generalización como negatividad}

Cuando aparecen los jóvenes, se los muestran con énfasis en lo negativo e invisibilizando una cotidianidad con rasgos positivos. Existe consenso en que la prensa se referiría a los jóvenes, en general, enfatizando lo negativo, aquello que constituiría un peligro para la sociedad en su conjunto o que confirmaría cierta irresponsabilidad y descontrol en el accionar juvenil. Se mencionan temas relacionados con «problemas de la juventud» como el embarazo adolescente, la drogadicción o el alcoholismo, lo que se refrendaría con estadísticas y opiniones de expertos que focalizarían en lo joven como objeto de preocupación (adicciones, descontrol) o motivo de amenaza (delincuencia).

En la prensa se ve a los jóvenes como que andan haciendo puras cagás, nada más, o si no como que no piensan (Lucas, grupo 1).

En el tema estudiantil, la protesta en sí, siempre se fijan en los destrozos y no se dan cuenta que, o no tratan el tema de que hay gente que está, no se po, peleando, exigiendo una mejor educación, y siempre se enfocan en hablar mierda de nosotros (Hans, grupo 4).

Principalmente los jóvenes aparecen haciendo vandalismo, destrozos (Evelin, grupo 5).

Siempre se muestra un rostro de los jóvenes, pero el lado feo, como la delincuencia en Chile (Cinthia, grupo 8).

El caso del embarazo juvenil, estadísticas duras en relación a cosas así, y lo otro que aparece harto: los jóvenes cuando hay un asalto (Hombre 3 , grupo 11). 
Siempre muestran a un joven en el diario [...] siempre lo muestran cuando crea desmanes o cuando se descarrila de alguna forma (Boris, grupo 16).

Los jóvenes juzgan el foco negativo de modo diferente en relación a si éste muestra verazmente la realidad. Para algunos, este tipo de noticias contienen exageraciones («la prensa exagera» es una afirmación recurrente), generalizaciones («hablan de algunos como si fueran todos», «no todos somos así»), y en ocasiones se le acusa de desvirtuar con afanes sensacionalistas («mienten», «la prensa busca vender diarios»). Sin embargo, también se le reconoce veracidad en algunos casos, en tanto presentaría situaciones indesmentibles en donde sí tendrían participación jóvenes, como es el caso de delitos, destrozos, irresponsabilidades, excesos y descontrol. No obstante, lo que es claro en los juicios emitidos, es que este énfasis en lo negativo por parte de la prensa, independientemente de su veracidad, exageración o falsedad, logra invisibilizar elementos positivos de la juventud que se expresarían, principalmente, en una cotidianidad en donde las actitudes solidarias, la organización con sentido constructivo y el esfuerzo en pro de la materialización de proyectos, serían elementos presentes.

Nunca se muestra como el lado lindo de los jóvenes, no sé, un grupo de jóvenes llevan un proyecto y no se po, les resultó bien, nada de eso (Cinthia, grupo 8).

[No se muestra] en lo que estamos los jóvenes hoy día. Las nuevas formas de pensar que tenemos los jóvenes, las formas de desenvolvernos que tenemos actualmente, a ese joven consciente no se le muestra $(\mathrm{Ca}-$ rolina, grupo 16).

Nunca muestran de las cosas buenas que se ponen a hacer los jóvenes, por ejemplo, voluntarios que los días de lluvia van y le dan comida a las personas en situación de calle (Nicolás, grupo 2).

Al hacer la relación entre lo que se enfatiza negativamente y lo positivo que se oculta, los entrevistados manifiestan un agravio frente al tratamiento que la prensa escrita hace sobre la juventud. En definitiva, se acusa a los diarios de estigmatización y de construir un estereotipo juvenil de rostro negativo, operación en la que los principales fantasmas de la sociedad actual serían presentados con rostro joven, obviando, por un lado, que muchos de esos aspectos serían transversales en 
lo etario, y por otro, que las valoraciones y esperanzas sociales también tendrían, a nivel cotidiano, una expresión en la juventud:

[...] muestran lo que quieren mostrar para que la sociedad en sí se forme un prototipo de juventud actual. $\mathrm{O}$ sea, ellos piensan que la juventud actual es mala, desordenada, borracha [...] y no es así (Nicolás, grupo 8).

Hay gente que hasta los sesenta años se siguen mandando embarradas de jóvenes. Entonces más allá del proceso de maduración personal se intenta decir que los jóvenes son el problema (Hombre, grupo 9).

\section{b) Generalización de juventud con sesgo de clase y enfocada en grupos medios y altos}

También se acusa generalización cuando se habla en genérico de «la juventud» atendiendo a características, conductas y tendencias de un sector socioeconómico particular que no es el popular. Ello sucedería principalmente cuando se hace mención a características neutras o positivas de una juventud que estudia y se recrea sin dañar ni preocupar al resto de la sociedad. En este punto destacarían apariciones sobre el uso de las tecnologías y conductas asociadas, cuestiones que si bien tocarían fundamentalmente a una juventud universitaria, de clase media y alta, con amplio acceso al consumo, serían presentadas, a juicio de los jóvenes entrevistados, cual si fueran reflejo de una generalidad juvenil. En tal sentido, vuelve a repetirse una afirmación: «la prensa generaliza» y en esa generalización «distorsiona» $\mathrm{y}$ «no nos considera».

No está hablando de los estratos más bajos esta noticia, como que siento que va dirigida a hablar de los estratos más altos [...] no refleja a la mayoría de los jóvenes, los y las jóvenes no están pensando ni en su universidad, están tratando de sobrevivir dentro de la urbe. Y aparte, la foto, también po, la miro y no veo ningún joven chiquitito, morenito, cachay. [...] No sé si todos los jóvenes tendrán acceso a tener internet en su celular a los quince años [...] una persona con un sueldo mínimo no sé si podrá darle a todos sus hijos un plan de celular (Constanza, grupo 3). ${ }^{3}$

Entiendo que se refieren a un solo segmento pero entendí como que el periodista en sí está generalizando, como que todos los jóvenes tienen como esas características (Hombre, grupo).

3 Los siguientes testimonios refieren a la noticia: «La generación Z llega a la universidad». La Tercera, Santiago, 12 de enero de 2013. 
Y gran parte de los medios se enfoca a estos jóvenes, no a nuestros jóvenes, no a los jóvenes que somos la mayoría de Chile, sino que a esta clase, los que tienen todo, los hijitos de papi (Hombre, grupo 10)

Pura gente, puros problemas de gente de plata poh. No sé, es como ver teleseries juveniles. Puras historias y aventuras de la clase alta (Hombre, grupo 11).

Sobre el tipo de joven yo creo que igual siempre se apela como a la clase media acomodada, que igual es como algo más aspiracional, que es más atractivo ver eso que verse quizás a uno mismo reflejado en los medios (Mujer, grupo 12).

Es una generalización que no abarca la realidad, o sea yo no sé de dónde sacaron que la mayoría de la juventud tiene acceso a computadores, internet y que nacieron con internet... (está) súper estereotipado y no responde a la realidad (Hombre 4, grupo 12)

O sea, la foto y lo que está escrito dentro de la noticia totalmente apunta a sectores más altos. Si una persona de escasos recursos lee esta noticia, qué sale, que nacieron con internet en la casa, que son sobreprotegidos, que van a ir a una universidad (Carolina, grupo 16).

No obstante, en el caso particular de las tecnologías de información y comunicación, los jóvenes entrevistados sí consideran que hay un uso cada vez más extensivo de ellas en los sectores populares, particularmente en personas que las necesitan por estudio o trabajo, o en quienes asumen la necesidad que les presenta la propaganda. Sin embargo, tienden a asociar dicho uso y conductas a las generaciones menores, los niños o de temprana adolescencia, negando que «nuestra juventud» tenga las características que la prensa generalizaría al hablar de «la juventud chilena» y al hacer un uso totalizador del concepto «generación joven».

Ahora todos los niños son presos de las consolas, están los video juegos, está el internet todo eso (Héctor, grupo 14).

Ahora los niños como que no se recrean con otros niños de su edad, sino que están encerrados con un tablet, un celular, en eso se lo pasan. Y antes, yo creo que, bueno yo tengo, como dije, 18, antes uno jugaba, como que se relacionaba con los niños (Patricio, grupo 6). 


\section{c) Mundo juveniles populares como sinónimo de vandalismo, desorden o banalidad}

Cuando aparecen culturas y estilos cercanos al mundo juveniles populares, ellos se presentan mayoritariamente como sinónimo de vandalismo, desorden o banalidad, sin ahondar en sus valores y distorsionando sus sentidos.

Se concluye que los estilos juveniles de expresión popular se estigmatizan, generalizando en lo malo y no incorporando un conocimiento mayor sobre sus códigos, valoraciones y prácticas. En el caso del hip-hop, ello ocurre con el grafiti, pues los jóvenes consideran que la prensa generaliza toda raya en la muralla como tal, lo que contradice los discursos y valoraciones que estarían presentes en la cultura hip-hop. En tal sentido, se estigmatizaría negativamente a los «verdaderos grafiteros» y a todo aquel que a los ojos de la sociedad se viste, escucha la música y tiene actitudes asociados a dicho o estilo. Lo mismo ocurriría en otras prácticas propias del hip-hop, un estilo particularmente presente en los sectores populares, como el caso del uso de patinetas, en donde la asociación entre quienes las portan y determinados delitos («lo atacó con una patineta» «el delincuente portaba una patineta») colaboraría con un estigma. En tal sentido, los jóvenes manifiestan agravio ante el hecho de que ciertos adultos teman a quienes sean identificados con el estilo hip-hop a causa de que la prensa habría homologado tal estilo con delitos y violencia. Lo mismo ocurriría con el punk, ya que se dice que la mención que se hace de él suele estar asociada a disturbios y eventos noticiosos en que punk se homologa a infractor de ley y joven potencialmente peligroso. Ideas como «la prensa nos estigmatiza» $\mathrm{y}$ «la prensa distorsiona», son, por tanto, recurrentes, de igual modo que lo es el juicio en torno a que los diarios no profundizan en las realidades juveniles populares, porque «no conocen» (ni investigan para ello) los valores, códigos y sentidos arraigados en sus culturas, errando, por tanto, en las categorías y descripciones que realizan.

[Se muestra] que los punk van a dejar la cagá a todos lados (Carlos, grupo 1$){ }^{4}$

4 Los tres primeros testimonios se refieren a la noticia: «Jóvenes punk se enfrentan a Carabineros en Barrio Bellavista». Radio Bío-Bío, 11 de marzo de 2013. 
Eso también lleva a estigmatizar al movimiento punk porque la noticia se enfoca totalmente en los hechos violentos, entonces si alguien lo ve en la casa va a decir ;oh! estos cabos que andan haciendo destrozos (Jandi, grupo 16).

El joven punk, podría haber sido cualquier joven que provocó incidentes pero recalca que es un joven que es punk (Carolina, grupo 16).

Primero que nada a esa noticia le falta una gran cosa: informar qué es el grafiti. Yo tengo muchos amigos que son grafiteros, pero mis amigos que son grafiteros no andan haciendo eso, eso no es grafiti. [...] Lo que realmente es el grafiti es arte, eso es vandalismo, entonces esa noticia ya perdió el rumbo [...] Una persona normal va a decir ¡ah pintaron un grafiti!, entonces va a ver un cabro que está pintando un grafiti y lo van a mirar feo porque está pintado un grafiti, igual que los de la noticia (Nicolás, grupo 5). ${ }^{5}$

O sea que (muestran que) era grafitero y delincuente. Como que si es un flaite tiene que ser ladrón, como que siempre generalizan todo, no explican bien lo que es cada uno (Lorena, grupo 5).

Yo cacho que si mi tata agarra un diario y ve «joven con patineta masacró a un carabinero», yo cacho que llego a mi casa y (me dice): quema tu skate, porque un cabro con un skate le pegó a un carabinero. Y eso ha aparecido, yo voy por el centro a veces y te lo juro, la gente me abre la vereda, me dejan pasar porque les da miedo que yo vaya con la tabla. [...] No pueden agarrar a todos por uno solo, eso es uno de los errores que cometen igual los periodistas. [...] Yo creo que los periodistas tienen que indagar más en el tema, en lo que es la juventud porque si no van a seguir mostrando lo mismo de siempre, lo malo de la juventud (Carlos, grupo 5).

Lo otro que se señala es que cuando el estilo aparece sin carga negativa se tiende a banalizar, haciendo notas que se juzgan como intrascendentes, que «no son noticias» o «no son importantes». En general, se plantea que aquello que oculta tanto la criminalización como la banalización de los estilos sería la cotidianidad y la cultura asociada a ellos, el cómo los jóvenes se reúnen y organizan a partir de los estilos, cómo desde ahí comparten elementos culturales que involucran arte,

5 Este y el siguiente testimonio refieren a la noticia: «Imponen castigo ejemplar a jóvenes que pintaron grafittis en patrimonio histórico de Villa Alemana». Radio Bío Bío, 29 de mayo de 2013. 
recreación y deporte; ejerciendo una ciudadanía activa con eje en las solidaridades colectivas.

Encuentro que es una noticia estúpida, no tiene mayor sentido para mí. Se supone que las noticias igual comentan o cuentan acontecimientos importantes, pa mí que alguien se corte el pelo no es importante (Sara, grupo 1$)^{6}$

Cuando estuvo el tema del incendio en Valparaíso muchos tatuadores se juntaron e hicieron la tatuatón. Se pusieron allá mismo en Valparaíso a rayar a cabros cobrando arroz, alimentos no perecibles, ropa, para ayudar a la gente y nunca lo vi en las noticias y fue una cuestión terrible de buena que estaban haciéndola una juventud que se ve rebelde. La otra vez hubo otra que fue también una tatuatón para ayudar a los cabros de allá de Talagante a que les den tablas de skate para poder practicar el deporte (Jorge, grupo1).

\section{d) La imagen del joven delincuente}

La imagen recurrente de un joven popular delincuente muestra realidades, pero oculta contextos.

Se identifica como aparición constante de juventud popular en los diarios, aquella que muestra a jóvenes infractores de ley que habitan las poblaciones pobres. Esta realidad juvenil, procesada como noticia, es reconocida por los jóvenes populares como verdad y realidad cotidiana. En otras palabras, se percibe que en este punto la prensa trata los entornos propios y expondría una cuestión cercana («conocemos cabros como los que aparecen en los diarios», «crecimos con cabros así»). Sin embargo, se manifiesta un agravio en un doble sentido: por una parte, se acusa a la prensa escrita de no profundizar lo suficiente en las realidades que aborda, y por otro, de estigmatizar a los pobres, y particularmente a los jóvenes pobres, asociándolos con un perfil delictual. Sobre lo primero, se dice que la cobertura de la realidad juvenil de los infractores de ley trata los hechos del delito y su sometimiento a la justicia, pero no los contextos sociales en que ellos se dan, el por qué se produjo que un niño llegara a la juventud como delincuente, las condiciones de vida de esos niños y jóvenes, y cómo la sociedad en su

6 Se comenta la siguiente noticia: «Descubra por qué hay tanta cabra rapada a un solo lado de la cabeza». Las Últimas Noticias, Santiago, 11 de octubre de 2013. 
conjunto tiene una deuda al respecto. Lo anterior se vincularía con el estigma, pues se plantea que una reducción del problema tratado naturaliza el delito en la figura del joven-pobre-delincuente, sin que explique su existencia. Dada esa situación, el que la prensa nombre los lugares populares en donde emergen estas figuras de «niños/jóvenes/amenazas» no haría más que reforzar los estigmas sociales sobre los sectores populares en general y sobre la juventud popular en particular. Una juventud que, de acuerdo a la opinión de los entrevistados, concentraría, en este tipo de noticias, la mayor parte de sus apariciones en la prensa.

Yo vengo de un lugar, de un sector como bien marginal y mi familia también se ha criado de forma marginal. De ahí han salido «Miguelitos» (María Paz, grupo 1). ${ }^{7}$

Falta poner el por qué. ¿Por qué Miguelito hizo eso? [...] A lo mejor los papás también fueron delincuentes, no tuvieron estudios, no tuvieron como alimentarse, tuvieron muchos hijos, el niño a lo mejor tenía que darle de alimentar a los demás y también a lo mejor ha hecho cosas buenas, pero muestran así como lo más terrible, lo más feo. Pero no dicen el por qué [...] la noticia es mala porque no da una noticia completa, sino que a medias (Mara, grupo 2)

Muestra los hechos que ocurrieron pero no muestran la realidad que vivió el niño o niña para haber llegado a delinquir (Oliver, grupo 7).

Siempre yo veo en estas noticias: «joven de Quinto Centenario»; «joven de población Carlos Condell»; «joven de población Pampa Alegre» y «joven de población Manuel Rodríguez». Lo primero que ponen es el sector. ¿Por qué? Porque así todos dicen entonces «iah! ... el sector es el malo...». Entonces te dicen: «Miguelito es delincuente porque viene de ese sector y entonces hay que alejarse de esa gente poh (Hombre, grupo 9).

Siempre las noticias se enfocan en todos los jóvenes delincuentes. Ya, está bien que muestren la realidad, porque aunque uno no quiera hay jóvenes que son así. ¿Pero no pueden mostrar a otros jóvenes que hacen escuelas de verano? [...] No indican esos jóvenes que ayudan a la comunidad (Yerko, grupo 14).

7 Los siguientes grupos comentan la noticia: «Miguelito es condenado por robo con intimidación». La Tercera, 20 de marzo de 2013. 
De qué me sirve leer eso a mí, no me sirve de nada, sé que es delincuente, si poh, si en mi población también hay. Entonces pienso que deberían haber más propuestas, más ayuda en el fondo pa este tipo de jóvenes y no mostrarlo así como un delincuente porque en el fondo es una víctima de todos, yo también pude haber sido así. [...] Como que aíslan el caso de Miguelito como un delincuente y todos somos culpables en el fondo (Nicolás, grupo 15).

\section{e) La prensa produce imágenes polares} sobre una buena y mala juventud

La prensa produce imágenes polares sobre una buena y mala juventud. En la juventud popular, la aparición predominante del joven delincuente solo es contrastada con la del «estudiante esforzado» o el «trabajador emprendedor», imágenes que en su idealización, ocultan las dificultades cotidianas y sistémicas de esta juventud popular.

Se sostiene que cuando aparece una juventud popular en modo positivo ello se hace en torno a determinadas imágenes ejemplares: «el joven esforzado en los estudios», el que participa cívicamente, «el deportista» que va a las olimpiadas, «el joven trabajador/emprendedor», imágenes que contrastan con las del «joven delincuente»o «problemático», aquel propenso a las adicciones, destrozos e irresponsabilidad. Se construirían, de ese modo y a decir de los jóvenes, imágenes polares de una buena y una mala juventud. No obstante, las apariciones ejemplares serían bastante más esporádicas que las definidas por lo negativo, de modo que no alcanzarían para contrastar una imagen hegemónica que se considera negativa.

Aparecen chicos del colegio y del liceo «cantaron en el corito», no sé qué, en el acto del alcalde. [...] Lo que se trata de mantener en los medios oficiales es una imagen fresca, bien orientada del joven, y la otra radicalizada en el sentido de: «Murió en un accidente», como terapia de choque: no tome, no maneje, no carretee, no salga a las marchas porque lo van a reprimir. Entonces hay como una polaridad (Hombre 5, grupo 11).

Esas son como las constantes en que los jóvenes son visibilizados en los medios, los estudiosos, los delincuentes, los esforzados y los flojos [...] siempre están esas etiquetas que apuntan a lo mismo finalmente, como al éxito y al fracaso en función del sistema (Mujer 3, grupo 12).

Se sostiene que las referencias a un joven popular estudioso, orientado por el esfuerzo que ello significa, sería algo que anualmente destacan 
las noticias sobre los resultados de la Prueba de Selección Universitaria, o PSU, aunque, se aclara, las historias de los mejores puntajes sigue siendo un relato inclinado a describir realidades de los grupos medios y altos. En este último sentido, la cobertura de la PSU evidenciaría las dificultades que enfrentan los jóvenes populares para acceder a la universidad. De todos modos, los casos ejemplares de jóvenes estudiantes populares que destacan los diarios, estarían remitidos a este tipo de ejemplos, cuya aparición, en el caso de los buenos puntajes PSU y de algunas competencias deportivas escolares - particularmente en provincia-, se darían una sola vez al año y en las mismas fechas, adquiriendo por ello un carácter tan estereotipado como predecible.

Lo otro que es importante es esta teoría del esfuerzo, o sea, el joven que junta esfuerzo es capaz de [...] (Hombre 4, grupo 11).

Yo creo que la prensa la mayoría de las veces a los jóvenes siempre les da un aspecto negativo, solamente una vez al año podemos ver (lo positivo) en el caso de cuando dan la PSU, los puntajes nacionales (Vale, Grupo 13).

En la PSU muestran las dificultades que (el joven popular) puede tener (Jandy, grupo 16).

Los jóvenes aparecen haciendo desmanes, destrozos, ahí es cuando más causan noticias. [...] Pero más allá, culturalmente o socialmente por otra cosa no, no hacen mucha noticia los jóvenes. [Excepciones serían] la PSU [...] que aparece una vez al año, los mejores, y una vez al año las olimpiadas cuando salen haciendo deporte (Evelin, grupo 5).

En la prensa por lo general siempre trata de recalcar lo más negativo de la juventud, y las únicas cosas positivas que muestran es cuando una vez al año sacan puntajes nacionales, pero nunca se van a acciones sólidas que van haciendo durante el año, siempre sólo una vez (Claudio, grupo 13).

Yo pienso que la intención de esta noticia [...] es que nos animemos, porque se espera que sean más jóvenes, más jóvenes puntaje nacional. [...] Es como dar esperanzas a la gente de que las cosas no son tan malas, la educación no está tan mal, hay tres puntajes nacionales. Pero veamos qué dice la noticia, son (de) colegios particulares, el apellido (de los jóvenes mencionados) no se puede ni pronunciar, entonces son 
noticias que no representan la realidad (Mario, grupo 15. Comentando noticia de puntajes nacionales). ${ }^{8}$

Por otro lado, entre quienes trabajan hay un consenso en torno a que su realidad juvenil no es presentada en los medios de comunicación escrita. Si bien se sostiene que cuando aparecen noticias sobre el trabajo y los jóvenes, esas noticias son, en general, «buenas noticias», y casi siempre relacionadas con la figura del «emprendedor» (alternativas de capacitación y tendencias relacionadas, por ejemplo), se plantea que ellas no reflejan los problemas de explotación e incumplimiento de los derechos laborales que sí afectarían a la juventud, particularmente a aquellos jóvenes que por necesidad deben trabajar por tiempo parcial mientras estudian. De este modo, se sostiene que en tal contexto, el énfasis dado a un emprendimiento idealizado como opción y camino del éxito, operaría en un doble sentido de distorsión y omisión: por una parte, ocultaría las dificultades concretas con las que se enfrenta la juventud trabajadora, y por otra, no consideraría el hecho de que los emprendimientos populares se gestan como posibilidad de sobrevivencia ante una condición económica extremadamente adversa («no queda otra») y no necesariamente como un desarrollo positivo y deseado.

Las cosas buenas que aparecen de los jóvenes son en relación al trabajo, el emprendimiento, pero no a los problemas que tienen los jóvenes en los trabajos, en los trabajos part time, eso no está reflejado en las noticias (Camila, grupo 3).

Mi grupo cercano y yo, todos somos emprendedores para costearnos también nuestra universidad, porque si estudias, ya sea en el colegio o en la universidad, los tiempos son muy limitados y un trabajo estable o dependiente no responde al mismo tiempo u horario que tu necesitai. [...] Entonces no te queda otra que emprender. Yo creo que es una salida, como una necesidad. [...] Para la sobrevivencia, necesitai lucas, vendis lo que podai, vendis en la universidad, vendis con los amigos, vendis en la feria, hacís malabares (Constanza, grupo 3). ${ }^{9}$

8 Comenta la siguiente noticia: «Los Lagos: tres jóvenes de Osorno obtuvieron puntaje nacional en la PSU» Radio Bío Bío, 27 de diciembre de 2013.

9 Los testimonios de Constanza y Javiera comentan la noticia: «Los jóvenes chilenos están cada vez más emprendedores». La Cuarta, 4 de diciembre de 2013. 
Yo creo que el uso de emprendedores es hacer como que suene bonito porque en realidad debería ser como no sé, esforzados, sacrificados, claro, es como para que suene positivo - eres un emprendedor-y te dan una palmada en el hombro (Javiera, grupo 3).

Hay una causal de demanda ganada de un empaque contra (el supermercado) Jumbo por un tema de legalidad, pero eso a nadie más le interesa. A mi gustaría que alguien viniera y dijera: esto sucede $[\ldots]$ a mí me gustaría que aparecieran las verdaderas condiciones laborales de los jóvenes en Chile (Carolina, grupo 3).

\section{f) La juventud popular: invisibilizada y distorsionada}

La juventud popular organizada es invisibilizada al enfatizarse aquella «que recibe» acción de voluntariado y no la «que gestiona» bienestar entre los pares. la juventud estudiantil organizada es distorsionada a partir del foco en los disturbios y la violencia.

Dentro del tipo de focalización negativa que se describe como propia de los medios escritos, uno de los ejemplos más recurrentes a los que se alude es el tratamiento de las acciones públicas del movimiento estudiantil, sosteniéndose que habría un énfasis mucho mayor en la violencia circunstancial que acompaña a las movilizaciones, que en las movilizaciones mismas y sus fundamentos presentes en los discursos estudiantiles. En ello, los estudiantes entrevistados enfatizan en que su organización y motivaciones no tienen lugar en la prensa, y que incluso produciendo eventos y acciones que objetivamente serían de trascendencia nacional, ello no es abordado por los medios. En resumen, aunque se reconoce que una de las principales apariciones de jóvenes en la prensa sería en relación al activismo estudiantil, se dice que ello se presenta distorsionando al movimiento mismo al encasillarlo, de modo totalizador, como accionar violento y vandálico.

En las marchas todos hablan de lo que sucedió después de las mismas marchas que hacen los jóvenes. Hablan de que rompieron un semáforo, de que se pelearon con los carabineros, que este carabinero salió herido, que éste está preso. No se centran en que la gente o que los mismos jóvenes están luchando por sus propios derechos (Javiera, grupo 3).

Yo me acuerdo el 2011 hubo una asamblea social, con cuatrocientas personas, que vinieron profesores y todo, estudiantes y toma, en El Carmela, y todo el asunto, y no salió en ninguna parte. No salió en absolutamente ninguna parte (Hombre 5, grupo 11). 
En lo que se refiere a las organizaciones poblacionales, los jóvenes pobladores entrevistados consideran que dicha realidad no es suficientemente tratada en los medios escritos, precisando que cuando ello ocurre, tiende a mostrarse a su juventud como receptora de programas y de acciones de voluntariado emprendidas por jóvenes no pobladores, sin destacar aquellas instancias en que la juventud pobladora gestiona sus propias iniciativas y proyectos.

Jóvenes se organizan para solucionar sus problemas habitacionales, no existe esa noticia (Hombre 6, grupo 11).

Apadrinamiento, siempre apadrinamiento, asistencialismo, entreguémosle cosas (Hombre 5, grupo 11).

\section{CONCLUSiOnes}

Del conjunto de conversaciones producidas en los dieciséis grupos de discusión realizados y tras su análisis, fue posible relevar un conjunto de conclusiones respecto a las significaciones y evaluaciones que los jóvenes populares urbanos realizan acerca de la prensa escrita y digital, y en lo que refiere a la forma en que esta trata el tema de los jóvenes en general, y de los jóvenes populares en lo específico.

En primer lugar, resulta destacable la significativa homogeneidad de las valoraciones generales respecto a la prensa escrita. Resultó notorio el alto nivel de coincidencia que los jóvenes manifestaron en cuanto a su distancia, desconfianza y rechazo frente a la producción informativa. Destacable resulta, al mismo tiempo, la coincidencia en la mayor valoración del formato digital, entendido por lo general como una fuente de información veraz, más cercana y con mayores niveles de credibilidad respecto a la prensa escrita y la televisión.

Las apreciaciones arriba indicadas resultaron coincidentes con independencia de factores estructurales tales como el género o la región de residencia de los jóvenes que participaron de los grupos, al igual como del factor identitario referido a la adscripción de los jóvenes al mundo del trabajo, estudiantil, organizacional o de algún estilo. Con independencia de estos factores, se percibe un fuerte nivel de homogeneidad en las percepciones, representaciones y valoraciones de los jóvenes respecto a la prensa escrita y digital.

Ahora bien, esta fuerte homogeneidad varía parcialmente toda vez que, al interior de esta discursividad compartida, es posible perci- 
bir la presencia, transversal al conjunto de los grupos de discusión, de argumentaciones asociadas a un sentido crítico de lo social en general que, si bien coincidentes en lo fundamental con las evaluaciones referidas, adquieren un nivel mayor de especificidad por cuanto articulan estas evaluaciones con un sentido crítico respecto al orden social en general. Es así como los atributos imputables a la producción noticiosa de la prensa adquieren un sentido, en estas argumentaciones, vinculado a la preservación del status quo, el «ocultamiento» de la realidad y la afinidad entre los intereses de la prensa y los de los grupos políticos y económicos «dominantes».

Esta presencia de lo que pudiéramos denominar como un subconjunto al interior del conjunto de argumentaciones de los jóvenes populares urbanos respecto a la prensa se replica al momento de la producción de evaluaciones acerca de la forma en que la prensa refiere a los jóvenes populares. En relación a esto, se observa una fuerte presencia de significantes como los de ocultamiento, invisibilidad, estigmatización, generalización, desconocimiento, banalidad y desprecio, significantes que en algunos casos va adicionada con interpretaciones que imputan una intencionalidad político-social de reproducción de las estructuras sociales existentes.

En definitiva, y a propósito de la interrogante respecto a la forma en que es evaluado el pluralismo desde el lugar de la recepción de mensajes noticiosos, el estudio realizado nos permite indicar que, en lo que refiere a la recepción que los jóvenes populares urbanos realizan sobre este indicador, la percepción generalizada es la de una ausencia significativa de expresión de la diversidad social, política, económica y cultural del país. La prensa, en este sentido, operaría más como un reproductor de las visibilidades e invisibilidades sociales. Y ello, para el caso de sujetos sociales condicionados por una doble condición de invisibilidad, constituye un balance en sus propias voces inequívoco.

SANTIAGO (ChILE), OCTUBRE 2014

RECIBIDO: OCTUBRE 2014 ACEPTADO: OCTUBRE 2014 


\section{REFERENCIAS BIBLIOGRÁFICAS}

BourdiEU, PIERRE (1999): «La juventud no es más que una palabra». En: Sociología y cultura. México D.F: Grijalbo/CNCA.

DuARTE, Claudio (2001): «iJuventud o juventudes? Versiones, trampas, pistas y ejes para acercarnos progresivamente a los mundos juveniles». C. DUARTE y D. ZAMBRANO: Acerca de jóvenes, contraculturas y sociedad adultocéntrica. San José: Departamento Ecuménico de Investigaciones.

MARGULIS, MARIO y MARCELO URResti (1996): «La juventud es más que una palabra». En M. Urresti (comp.): La juventud es más que una palabra. Ensayos sobre cultura y juventud. Buenos Aires: Biblos.

Miguel De Busto, JuAN CARLOS (2004): «Sobre pluralismo y diversidad». Zer. Revista de estudios de comunicación.

MURCIANO, MARCIAL (2007): «Las políticas de comunicación ante los retos del nuevo milenio: Pluralismo, diversidad cultural, desarrollo económico y tecnológico y bienestar social». Zer. Revista de estudios de comunicación $\mathrm{N}^{\circ} 20$.

RuIZ-TAGLE, P. (2011): «Propiedad de los medios y principios de intervención del Estado para garantizar la libertad de expresión en Chile». Revista de Derecho $\mathrm{N}^{\circ}$ 2. Universidad Católica del Norte.

SIERRA, LUCAS (1997): «Pluralismo y comunicación social: libertad de expresión y dos conceptos de libertad». Revista de Derecho, Vol. VIII. Universidad Austral de Chile.

SKINNER, QUENTIN (1973): «The empirical theorists of democracy and their critics: A Plague on Both their Houses». Political Theory, Vol. 1, No3. 